- 15-17 de febrero de 2017 nano tech 2017

Tokyo Big Sight. Tokio, Japón

<http://www.nanotechexpo.jp>

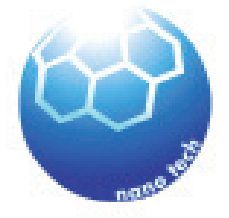

\title{
nano tech 2017
}

Intemational Nanotechnology Exhibilion \& Conference

- 5-6 de marzo de 2017

ICNN 2017: $19^{\text {th }}$ International Conference on Nanoscience and Nanotechnology

Hotel NH Roma Villa Carpegna. Roma, Italia

<https://www.waset.org/conference/2017/03/rome/ICNN>

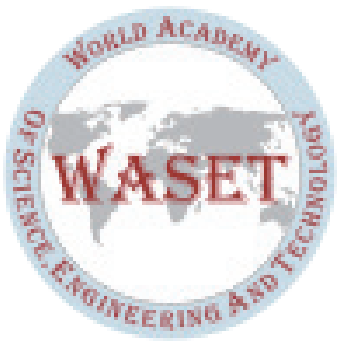

- 28-30 de junio de 2017

Nanotech France 2017

París, Francia

<www.nanotechfrance.com>

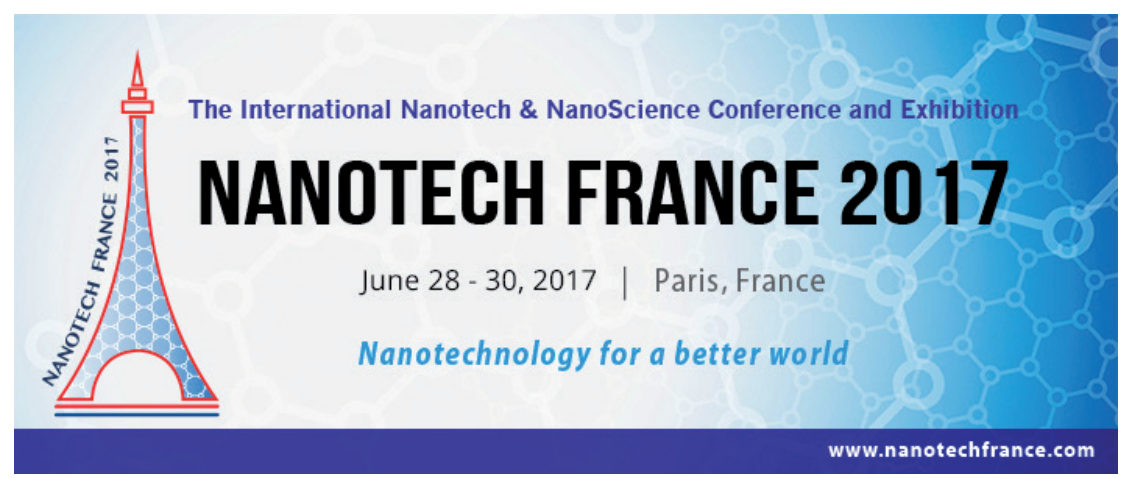


Mundo Nano | Eventos | vol. 9, No. 17, julio-diciembre, 2016 | www.mundonano.unam.mx

- 5-7 de abril de 2017 $4^{\text {th }}$ World Congress and Expo on Nanotechnology and Materials Science Tryp Barcelona Apolo. Barcelona, España <http://www.worldnanoconference.com/>

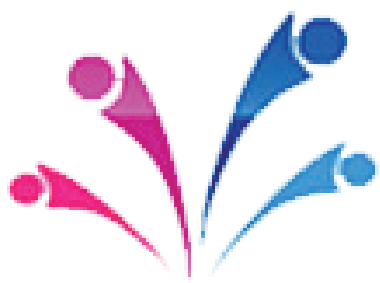

- 14-17 de mayo de 2017

Nanotech 2017. Conference \& Expo

Gaylord National Hotel \& Convention Center

<http://www.techconnectworld.com/Nanotech2017/>

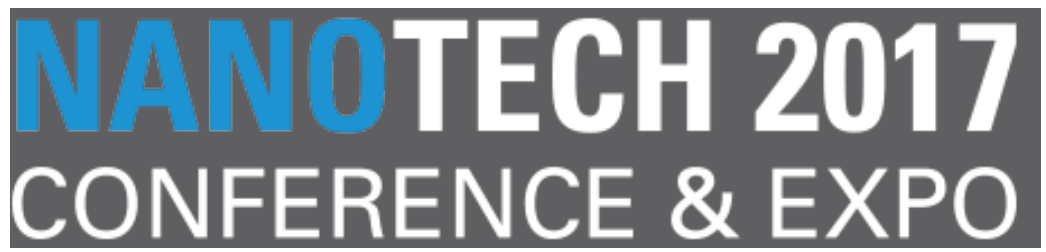

- 21-23 de junio de 2017

\section{EuroNanoForum}

Mediterranean Conference Centre. Valletta, Malta

<http://euronanoforum2017.eu/>

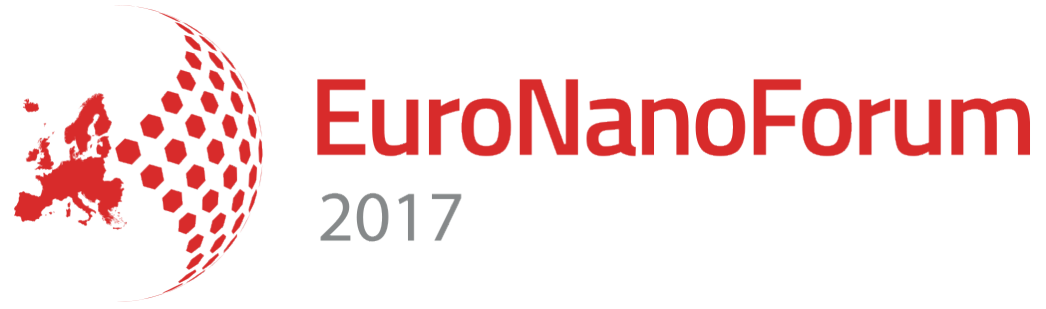


- 1-8 de julio de 2017

Nanotexnology 2017. International Conferences \& Exhibition on Nanotechnologies - Organic Electronics \& Nanomedicine

Porto Palace Conference Centre \& Hotel. Thessaoniki, Grecia

$<$ http://www.nanotexnology.com>

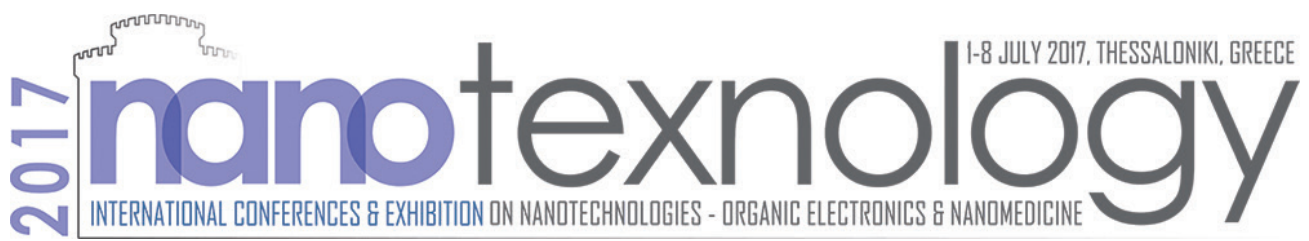

- 20-25 de agosto de 2017

XXVI International Materials Research Congress - 2017

JW Marriott Cancun Resort \& Spa y CasaMagna Marriott Cancún Resort.

Cancún, México

<https://www.mrs-mexico.org.mx/congreso.html>

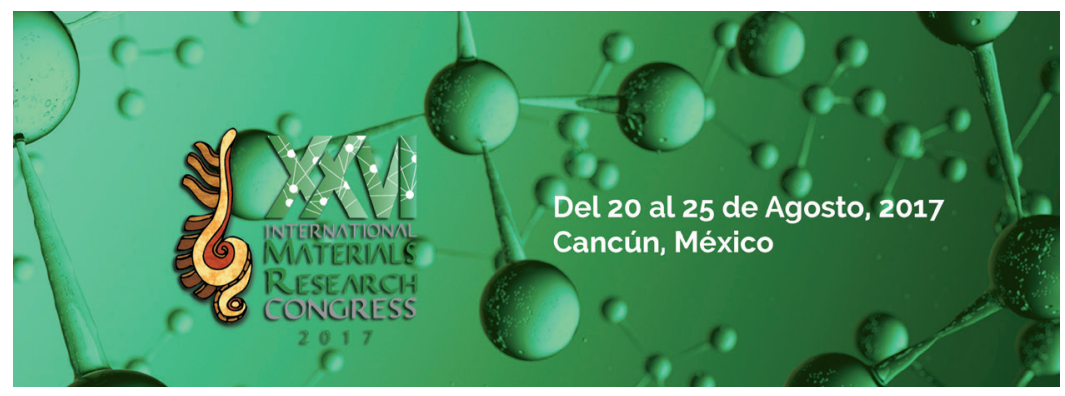

- 27 de agosto-1 de septiembre de 2017

$18^{\text {th }}$ International Conference on Luminescence

Peota Ronaldo Cunha Lima Convention Center. João Pessoa, Paraíba, Brasil <https://icl2017br.com/>

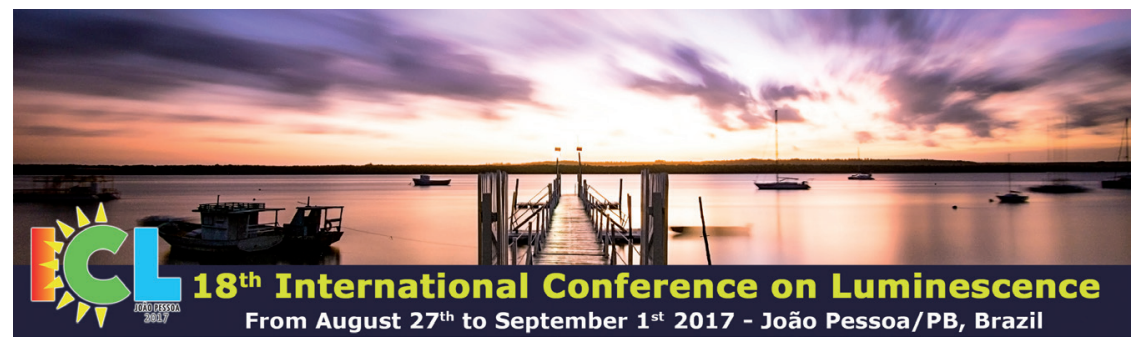

From August $27^{\text {th }}$ to September $1^{\text {st }} 2017$ - João Pessoa/PB, Brazil 
Mundo Nano | Eventos | vol. 9, No. 17, julio-diciembre, 2016 | www.mundonano.unam.mx

- 13-14 de noviembre de 2017 $22^{\text {nd }}$ International Conference and Expo on Nanoscience and Molecular Nanotechnology

Flemings Hotel Wien-Westbahnhof. Viena, Austria

$<$ http://nanotechnology.conferenceseries.com/>

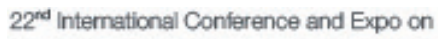

Nanoscience and Molecular

Nanotechnology

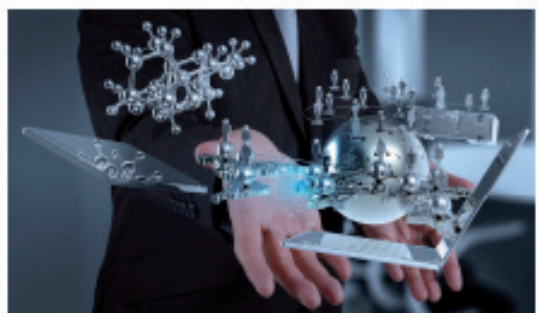

